\title{
Adaptive Exoskeleton Systems: Remodelage for Social Housing on Piazzale Visconti (BG)
}

\author{
Oscar E. Bellini
}

\begin{abstract}
To promote the renewal and sustainable requalification of social housing in Lombardy means to carry out research in order to identify solutions as efficient and effective as possible, which do not involve the demolition of the building but promote its enhancement. Today it is possible to intervene on existing buildings with new strategies which give all-round and multipurpose solutions to the general issues, using techniques that go beyond punctual interventions and extend the useful life cycle of the built environment. The seismic upgrade must be at the basis of every project within construction. Thanks to an adaptive exoskeleton system it is possible to innovate the architectural image, to support an equitable and sustainable development based on the prevention and risk management connected to unexpected seismic events and to guarantee aspects of structural safety and physical integrity of the users, to improve the morphological, spatial and typological organization of buildings. By using an exoskeleton system, it is possible to innovate the architectural make-up, to support an equitable and sustainable development based on the prevention and the risk management connected to unexpected seismic events. A way to take into due consideration the now unavoidable aspects of structural safety and physical integrity of the users. This paper, part of a Departmental Study, presents the first guidelines to the renewal of social housing buildings owned by Aler Bergamo, Lecco, Sondrio on Piazzale Visconti in Bergamo.
\end{abstract}

Keywords Social housing • Exoskeleton - Built environment • Integrated design • Resilience

O. E. Bellini (凶)

Architecture, Built Environment and Construction Engineering — ABC Department, Politecnico di Milano, Milan, Italy

e-mail: oscar.bellini@polimi.it 


\section{A New Strategy to Build In and On the Built}

We are an extraordinary and beautiful country but at the same time very fragile. [The landscape is fragile and Cities are fragile, especially suburbs where no one has spent time and money to maintain them. But it is precisely the suburbs that are the city of the future, $[\ldots]$ one that we will bequeath to our children. We need to carry out a monumental project of "mending" and we need ideas. (Piano 2014)

This important statement by the Italian architect Renzo Piano underlines the strategic importance of intervening in the obsolete construction of our suburbs and introduces the imperative and need to put forward new ideas to pursue the objective now recognized on the political, economic and disciplinary level to intervene in the built environment ${ }^{1}$ (Murie et al. 2003).

Few are the designers who have the skills and professionalism to know what to do about the enormous, at least in terms of size, built heritage present in these realities starting from the great real estate assets, such as public housing. This enormous building heredity, which dates back to the second post-war period, now constitutes a significant part of our suburbs in terms of quantity, and it must be "adjusted", in line with a much needed responsible initiative. ${ }^{2}$ This paper describes a pragmatic proposal for the redesign of post-Second World War buildings based on the most recent international experiences and provides an operational instrument for the "integrated" and "adaptive" redevelopment of built environments: on a structural, technological, typological, morphological, functional, performance, economic and social level of social housing real estate. ${ }^{3}$

\section{Integrated Design in Social Housing: Looking for a New Balance}

According to scientific literature, there are different ways of intervening on built environments without resorting to demolition. These methods can be traced back to key attitudes, which must absolutely be integrated with one another, so that the

\footnotetext{
${ }^{1}$ In 2017, the European Union Prize for Contemporary Architecture-Mies Van der Rohe Award was awarded to a Dutch project for the renovation and rental of a social housing building. The award was given to NL Architects, XVW Architecture kleinburg DeFlat, Amsterdam, 2013-2016. Although in Italy social housing is less developed than in other European countries, it still represents a far from negligible asset with performance deficits that are largely the same as those of private assets. This means the study field should extend to include the entire housing sector.

${ }^{2}$ Building rehabilitation projects are interventions to create new dwelling habits, new uses, new functions and new aesthetic and architecture solutions.

${ }^{3}$ The European Committee for the Promotion of Housing Rights considers social housing as services provision for those without access to the housing market in order to reinforce their position within the community. It is possible to associate the term "social housing" with the public housing sector.
} 
project intervention can have value (Zambelli 2004; Grecchi 2008; Malinghetti 2011; Ascione 2012; Perriccioli 2015; Paris and Bianchi 2018).

The priority intervention concerns the structural system of the building. In a country with a high seismic risk like Italy, it is essential to approach constructions by facing this criticality, in which many situations present itself as a priority that could undo all the other retrofit actions of the building, starting from economic ones. An adaptive exoskeleton can be used to improve this aspect, promoting these actions and improving the situation. It is a device inspired by the external structure of certain invertebrates, similar to medical prosthetic support, which intervenes in the deteriorated parts, restoring and implementing its characteristics and performance.

Applied to buildings, it defines an independent volumetric expansion, thanks a structure of autonomous foundations, to be juxtaposed to the façades, where it creates new spaces and volume. It can act as a support to a new rooftop architecture, additional shaped boxes or new floor surfaces to rethink dwellings.

The adaptive exoskeleton can help interventions on a variety of levels: structural, as a system for static and seismic strengthening; energetic, as a device used to reduce consumption and the environmental impact and to increase living comfort; typological, in terms of an opportunity to reorganize and redesign dwelling-sizes; functional, as an opportunity for the inclusion of new horizontal and vertical connections and architectural, for the technological rethinking of the interface between the inside and outside of the building. ${ }^{4}$

In order to use the exoskeleton system, we must carry out an accurate analysis with regards to feasibility analysis and convenience of the intervention, not only for economic reasons but also for an ecological opportunity, in order to take into account, the environmental "costs" resulting from any demolition or reconstruction (Boeri and Longo 2012). In terms of energy eco-efficiency, adaptive exoskeletons are to be preferred to a "radical construction solution"-which demolishes in order to reconstruct—since they minimize, from the initial stages of the design, the use of raw materials and reduce yard waste debris.

Today, the main techniques for seismic reinforcement are referable within a local approach, which consists in the consolidation of the structure with a punctual strengthening of the frame nodes, beams and pillars and in the global approach, in which the building is retrofitted using the addition of earthquake-resistant elements.

While punctual reinforcement interventions are very expensive, invasive and destructive, the adaptive exoskeleton is applied from the outside of the building and can be economically more convenient if integrated with other retrofitting interventions. The exoskeleton structure can be added to buildings working from the outside in the form of a double skin. This can be designed in two alternative ways: (a) integrating additional bracing walls within the exoskeleton (walls solution); (b) designing the exoskeleton itself as an earthquake-resistant box-shaped system (shell

\footnotetext{
${ }^{4}$ This constructive solution is very similar to the design research and the works of the French architects Lacaton and Vassal.
} 
solution). The choice of the structural solution depends on the initial stiffness of the building and may be conceived as over-resistant or dissipative. The box-shaped solution allows for the reduction of the stresses in the elements, by reducing the thickness of the additional skin and the adoption of specific elements with the double objective of improving energy efficiency along with the safety of the building. The wall solutions include, among others, the use of braces or walls with rigid or dissipative connections, walls hinged at the base, rocking walls, adaptive seismic walls and dissipative braces. The shell solution involves the creation of a new skin, a diaphragm in which the entire façade structure becomes an earthquake-resistant element (e.g. upgrade of grid shell and curtain wall or coating with resistant panels) (Marini et al. 2016; Passoni 2016; Scuderi 2016).

These techniques, integrating and overlapping on a holistic basis, can produce a lot of effects and benefits at different levels. They (a) allow for the upcycling of the building structure, improve seismic resistance and resilience; (b) reduce the environmental impact associated with seismic risk; (c) increase real estate value; (d) protect the long-term economic investment, which could be compromised by the damage caused by earthquakes; (e) reduce the cost of restructuring due to increased resilience; ensure the coexistence in a single construction site of the architectural, structural and energy renovation; (f) cancel out costs for the relocation of residents during the work by intervening on the outside; $(\mathrm{g})$ allow for the addition or expansion of housing (rooftop, addition, etc.), thanks to new indoor and outdoor surfaces, the sale of which can partially compensate the renovation costs; (h) promote urban densification policies, through volumetric expansions, by reducing the consumption of land; allow for the morpho-techno-typological redefinition of the building, that can be redesigned in its vertical and horizontal connecting elements; (i) promote urban regeneration; create more pleasant, sustainable and resilient environments (Bellini et al. 2018). To increase the environmental value of the renovation, it is fundamental to reconsider the operational approaches within the life cycle thinking, aiming at maximizing performance and minimizing the impacts and environmental costs of the building life cycle (Antonini et al. 2011; Bellomo and Pone 2011; Paris and Bianchi 2018).

In addition to protecting the static aspects and monitoring the borderline states of the system (performance-based design), the structural design refers to the choice of materials - eco-efficient and recyclable_and technologies-prefabricated, dry, reparable and adaptable - according to principles of minimization of the environmental and economic impacts (life cycle assessment and life cycle costs), implementing the concepts of system sustainability and resilience (Bellini et al. 2018). 


\section{Objectives and Aims of the Research and Sourcing Process}

The Departmental Study, financed by Aler ${ }^{5}$ Bergamo, Lecco, Sondrio and entitled "Preliminary guidelines for seismic resilience and urban regeneration, through an adaptive exoskeleton, of the settlement of public social housing on Piazzale Ermes Visconti", aims to explore the possible technical solutions to improve the housing, quality and technological performance of the buildings in Bergamo, without resorting to total demolition and subsequent reconstruction from scratch. ${ }^{6}$

The Aler's need is above all to identify constructive guidelines to be used on buildings without having to relocate the tenants residing in their own homes.

In this context, after a series of studies and analyses of the buildings, a multifaceted approach was proposed to Aler. The aim of the work is to investigate the solutions and systems to rehabilitate Aler real estate and to verify how it could be implemented by adopting an innovative strategy: a sort of prosthesis, an adaptive exoskeleton to be applied to the social housing buildings.

Aler wanted to use a paradigmatic solution that was adaptable to its decaying buildings. A solution that can easily be modified over time to integrate new social, economic and urban conditions. An open system that helps buildings respond to environmental, economic, functional and social challenges. Not a solution that crystallizes the building's image and prepares it for its future obsolescence but a "radical solution". A design process and method that increases the settlement density of the urban block, without consuming new ground. The guidelines proposed to use an adaptive exoskeleton: an independent but collaborative anti-seismic structure. ${ }^{7}$

The first step is to improve the quality of the buildings and to facilitate the new functional and typological layouts required over time by the local users. This system is designed to extend the building's life cycle through a gradual adaptation that reduces the effects of environmental stress on the building and spreads it out over a longer time span. This system is a structure of metal scaffolding that can be applied and connected to the buildings that require rehabilitation. It is important to emphasize how this technology relies on "dry assembly" and reversible technological solutions that allow for cost reduction and recycling of building materials and provide a viable alternative to the building replacement and its high environmental impact.

\footnotetext{
${ }^{5}$ ALER (Agenzia Lombarda Edilizia Residenziale) is an Agency that promote and manage social housing in the Lombardy Region.

${ }^{6}$ The urban block covers an area of about $5,500 \mathrm{~m}^{2}$ and occupies a strategic position at "Villaggio degli Sposi". It has a regular shape and a good supply of vegetation. The urban block is entirely occupied by social housing which are not well maintained nor well preserved. The buildings are arranged in an L shape and are composed of $24(16+8)$ houses with stairs and no elevators. The buildings were built with a masonry structure made of blocks of load-bearing bricks in the early '50s and they are critical from an energetic, structural and technologic point of view.

${ }^{7}$ Norme tecniche per le costruzioni, NTC, 2008. D.M. January 14, 2008.
} 
The exoskeleton may perform both a two-dimensional action through the definition of façade refurbishment (recladding, refitting and overcladding) and a threedimensional action defined by volume additions (individual boxes, bioclimatic greenhouses towers and continuous or overall additions) (Guidolin 2016).

The guidelines proposed by Visconti aim to be a pursuit of cross-disciplinary design instruments for the achievement of "holistic and integrated regeneration" for public social housing. They want to be an articulated map of mediations and insights about strategies to build in and on the built environment, based on two fundamental aspects: the first is supported by sociological positions according to which a refined and careful designed environment produces a sense of place implicitly as its own, it follows that the rehabilitation action assumes a value of raising the social position even before the economic value of the area or of the building. The second - the maximization of resources - is part of the broader theme of respecting the environment which is supported by actions such as attention to land use and the definition of technical/technological solutions aimed at active and passive energy saving.

The rehabilitation project has shown that the interpretation of emotional and physical roots of the inhabitants in relation to their everyday life becomes a plus towards both the housing and the urban landscape transformation if in addition to these results there are clear and well-defined strategies in terms of execution, reliability, management and funding. This study's primary aim is to show the feasibility of the building rehabilitation approach not only in energetic terms but primarily in relation to the quality increase of structural safety and housing services.

The definition of the metadesign intervention for the "Remodelage" 8 of the Aler lodgings on Piazzale Visconti was based on the following aspects: (a) general aspects: the process of building rehabilitation can be an interesting topic from several points of view because it is closely related to other issues such as economic recovery and employment, urban regeneration, cohesion and social participation. The recovery of social unease in the social housing of Piazzale Visconti must be tackled minimally with the simple building recovery of dwellings bordering on the urban decay. The provision of outdoor collective spaces in agreement with the dignity of the person and designed for "public social housing" can lead, as well as to social assistance programs, to an improvement of their condition. (b) Technical aspects: the energy aspect is only one important variable in the process as it has many funding opportunities, but at times, it can seem to limit. ${ }^{9}$ Thus, the first action that has been proposed to Aler concerned the structural system of the buildings on Piazzale Visconti (Figs. 1 and 2).

\footnotetext{
${ }^{8}$ The team was created by Roland Castro for the regeneration of the Grands Ensembles in the French banlieues. Castro and Denissof (2005), [Re]modeler, Métamorphoser, Le Moniteur, Paris.

${ }^{9}$ Instead the systemic approach is most evident in this project: the REHA-PUCA French program which aims at identifying innovative solutions suitable for building rehabilitation of sample buildings through a competition open to groups made up of designers and contractors. Three guidelines are identified: diversification, management and densification, interpreting the economy of territorial space in order to avoid further land use.
} 


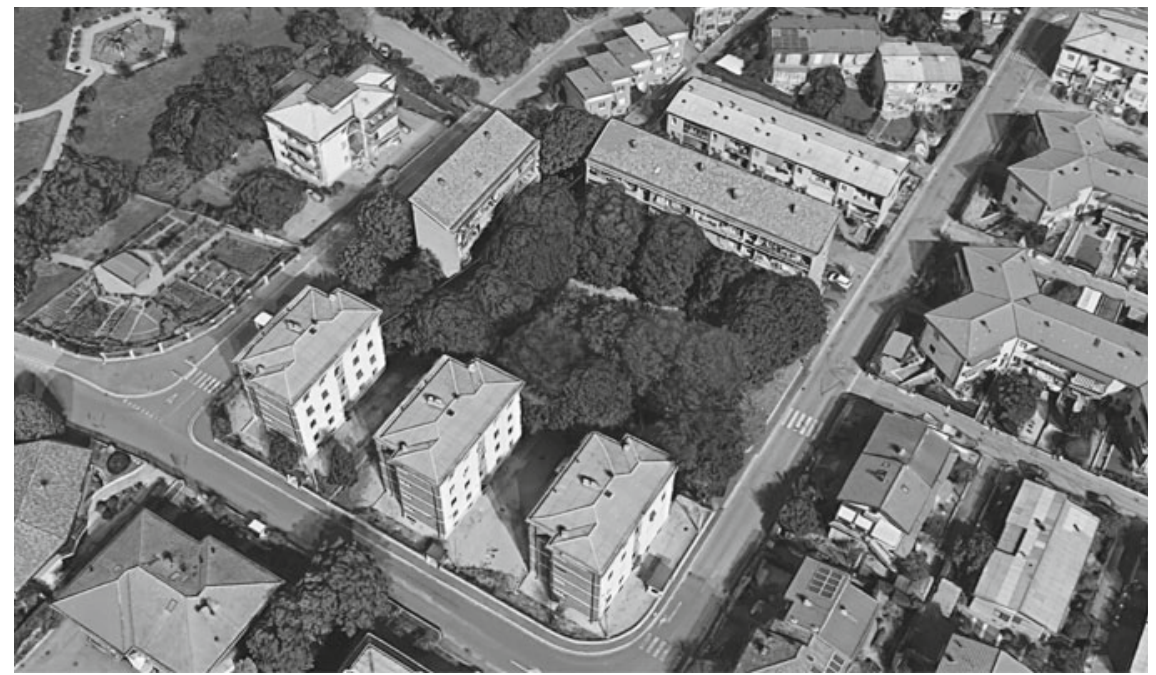

Fig. 1 Urban block of Piazzale Visconti with five buildings dedicated to public social housing. The three identical buildings are owned by the Municipality of Bergamo; the others belong to Aler

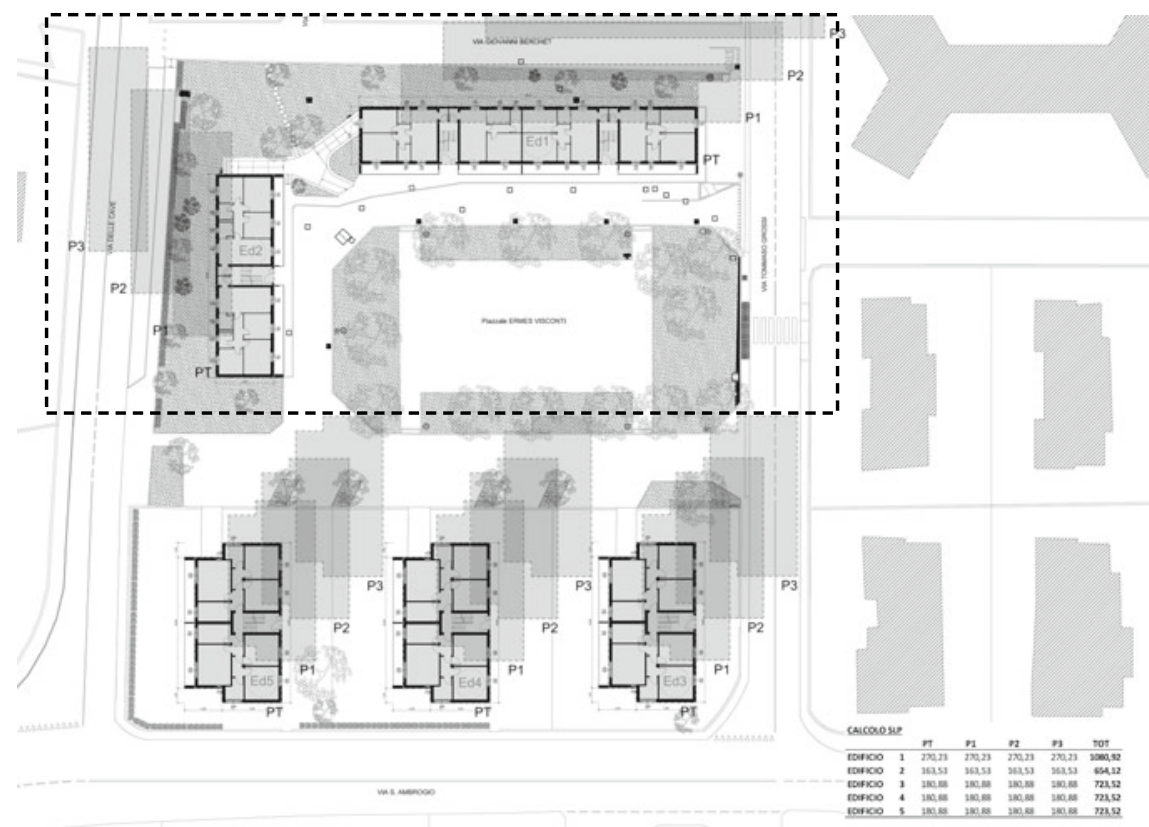

Fig. 2 Topographic survey of the Piazzale Visconti block and quantification of the new building volume. The entire block is intended for public housing 
This leads to preventive practices that reduce structural vulnerability to seismic actions, planning methodologies that promote a rational use of resources, an enhancement of the built environment and the preservation of human life (Marotta and Zirilli 2015). Interventions that provide an alternative to the traditional "scrapping/demolition" and transcend the practice of "abandoning what does not work". It is possible to exceed the ideological dilemma between demolition/conservation and inaugurate a "third way". A design method which today is prefigured in Parasite, Rooftop and Hybrid architecture (Boeri and Longo 2012; Angi et al. 2012; Angi 2016a, b; Montuori 2016).

The project contents go beyond the conventional methods that define sustainability as related just to an energy upgrade, by introducing solutions on the structural safety and stability aspects relating to the increasingly frequent seismic phenomena as well (Marini et al. 2016). The sustainability of an intervention is also related to the impacts of damage and collapse due to possible earthquakes during the life cycle of the retrofitted building (Murie et al. 2003; Feroldi 2014; Belleri and Marini 2016).

In the disciplinary debate, ranging from "scrapping" to "mending", it appears reasonable to use the potential of the adaptive exoskeleton system (Marini et al. 2017). In this way, it is possible to integrate a design approach that allows to implement the resilience of buildings. This device improves the performance, through an external supporting and cooperating prosthesis, which is not simply earthquake resistant, but also technological, considering that it facilitates the realization of "double integrated skin solutions" with which to obtain a new frontier between exterior and interior, in order to improve energy efficiency and promote the architectural restyling of the building (Guidolin 2016). The use of the exoskeleton facilitates the morpho-technotypological rethinking of the existing structure and allows for the activation of urban densification policies (Boeri and Longo 2012) and for the urban regeneration of the social and functional substrate (Di Giulio 2013).

\section{Conclusions}

The research on social housing buildings on Piazzale Visconti aims to demonstrate the potential to use innovative technical strategies for the rational maintenance of real estate directed at the architectural recovery and reconfiguring of social housing stock, improving the performance and quality of the environment built.

Today, it is possible to apply retrofitting processes in opposition with demolitions and reconstructions, above all in terms of social and environmental costs.

We have articulated social, economic and technological critical situations, in which it is possible to adopt external structures to help the integrated refurbishment. This device is the exoskeleton system. 
It allows for construction from outside the building minimizing inside work within the housing unit. It is an "innovative device" to connect technological and social issues in the organization of a particular building site management process. It allows for the regular execution of building functions, thus containing the costs of the building site.

The exoskeleton systems can have different configurations. It allows users to achieve sufficient settlement density, creating the possibility of carrying out new housing. It is an external structural grid that gives the designer and user a certain level of customization freedom, above all in terms of the morphological and functional configuration of the façade, which can be read as an interface system between private interior space and public space.

The adaptive exoskeleton systems are able to create balconies, greenhouses, etc.; technological elements for shading control can be added; the architectural morphology and typology can be reconfigured and some customized functions can be considered. It is possible to get a new building: a new architecture (Fig. 3).

The integrated rehabilitation actively involves users and designers, through a device that connects technological innovation and social need for involvement, in order to assign an active role to the user in a process through which they are strictly interested in providing a new aesthetic identity to buildings. A design process that requires significant disciplinary skills: skills that today Department of Architecture, Built environment and Construction engineering of the Politecnico di Milano can provide. 
(a)
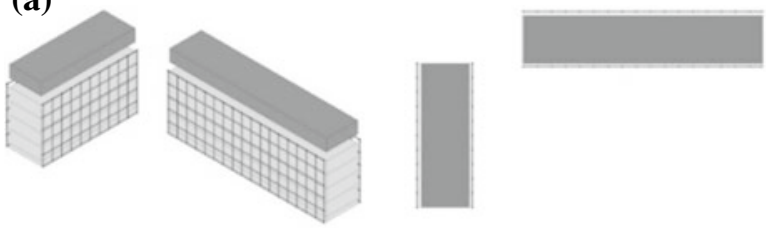

Solution for twodimensional exoskeleton application solution, in which to apply rooftop architecture, façade refurbishment, recladding, refitting, overcladding for retrofit.

Solution for threedimensional exoskeleton

(b)
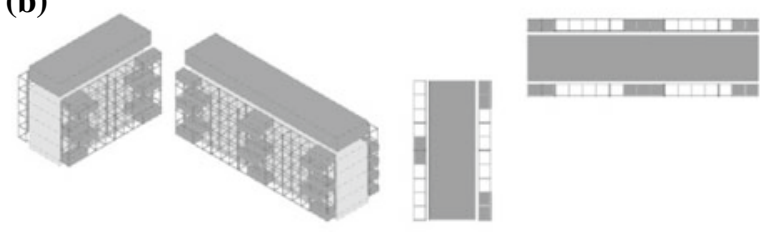
application, where the concept is to build rooftop architecture, punctual boxshaped (box, loggias, balconies, greenhouses etc.) and to redesign indoor dwellings.

(c)

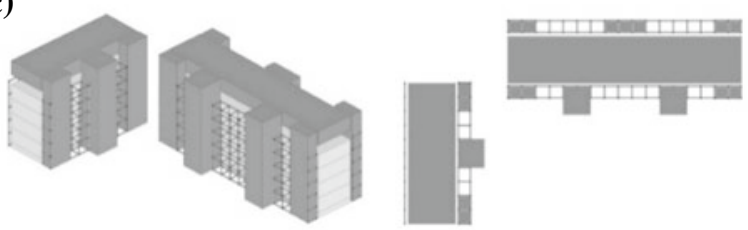

Solution for threedimensional exoskeleton application, where the concept is to build rooftop architecture, new boxes, loggias, balconies, greenhouses etc., to redesign indoor dwellings and staircases, lifts etc.

(d)
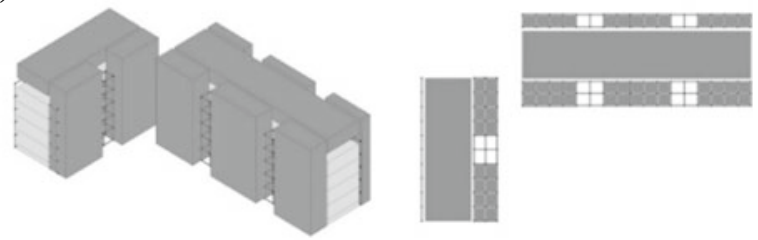

Solution with a threedimensional exoskeleton application, where the concept is to build rooftop architecture, to double up floor levels creatinine a new gallery,

(e)
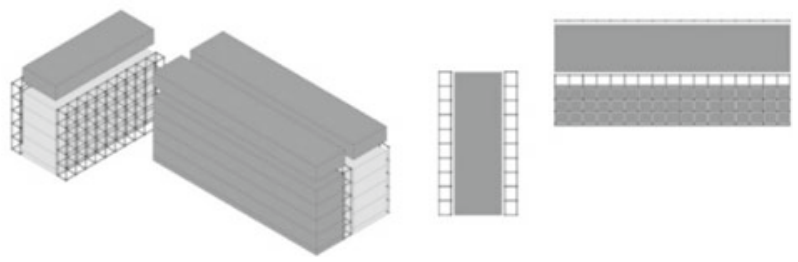

Solution with a threedimensional exoskeleton application, where the concept is to build rooftop architecture, doubling floor levels with a central corridor building type and new dwellings increasing urban density and residents

Fig. 3 Five morpho-techno-typological solutions obtainable by adaptive exoskeleton system 


\section{References}

Angi, B. (2016a). Amnistia per l'esistente. Strategie architettoniche adattive per la riqualificazione dell'ambiente costruito. Siracusa: LetteraVentidue Editore.

Angi, B. (Ed.). (2016b). Eutopia urbana/Eutopia Urbanscape. Siracusa: LetteraVentidue.

Angi, B., Botti, M., \& Montuori, M. (2012). "Eutopia urbana. La manutenzione ragionata dell'edilizia sociale" Abitare il nuovo/Abitare di nuovo ai tempi della crisi, Clean Edizioni. In Abitare il nuovo/Abitare di nuovo ai tempi della crisi, 12-13 dicembre 2012 (pp. 1771-1785). Università degli Studi di Napoli Federico II-Dipartimento di Progettazione Urbana e Urbanistica.

Antonini, E., Gaspari, J., \& Olivieri, G. (2011). "Densifying to upgrading: Strategies for improving the social housing built stock in Italy". Techne, 4, 306-314.

Ascione, P. (2012). Cognitive study and upgrading of the 20th century architectonic heritage: Experiences and methodologies. Techne, 3, 250-261.

Belleri, A., \& Marini, A. (2016). Does seismic risk affect the environmental impact of existing buildings? Energy and Buildings, 110(1), 149-158.

Bellini, O. E., Marini, A., \& Passoni, C. (2018). Adaptive exoskeleton systems for the resilience of the built environment. Techne, 15, 71-80.

Bellomo, M., \& Pone, S. (2011). Technological retrofit of existing buildings: Dwelling quality, environmental sustainability, economic rising. Techne, 1, 82-87.

Boeri, A., \& Longo, D. (2012). From the redevelopment of high-density suburban areas to sustainable cities. Architectoni.ca, 2, 118-130.

Castro, R., \& Denissof, S. (2005). [Re]Modeler, Métamorphoser. Paris: Le Moniteur.

Di Giulio, R. (2013). Paesaggi periferici. Strategie di rigenerazione urbana. Macerata: Quodlibet Studio, Città e Paesaggio.

Feroldi, F. (2014). Sustainable renewal of the post WWII building stock through engineered double skin, allowing for structural retrofit, energy efficiency upgrade, architectural restyling and urban regeneration ( $\mathrm{Ph} . \mathrm{D}$. thesis). University of Brescia.

Grecchi, M. (2008). Il recupero delle periferie urbane. Da emergenza a risorsa strategica per la rivitalizzazione delle metropoli. Rimini: Maggioli.

Guidolin, F. (2016). Taxonomy of the redevelopment methods for non-listed architecture: From façade refurbishment to the exoskeleton system. In A. Caverzan, T. M. Lamperti, \& P. Negro (Eds.), A roadmap for the improvement of earthquake resistance and eco-efficiency of existing buildings and cities, Proceedings of Safesust Joint Research Centre (pp. 97-102). Ispra.

Malinghetti, L. E. (2011). Recupero edilizio. Strategie per il riuso e tecnologie costruttive, Il Sole 24 Ore, Milano.

Marini, A., Passoni, C., Belleri, A. Feroldi, F., Preti, M., Metelli, G., et al. (2017). Combining seismic retrofit with energy refurbishment for the sustainable renovation of RC buildings: A proof of concept. European Journal of Environmental and Civil Engineering, 1-20.

Marini, A., Passoni, C., Belleri, A., Feroldi, F., Preti, M., Riva, P., et al. (2016). Need for coupling energy refurbishment with structural strengthening interventions. In B. Angi (Ed.), Eutopia urbanscape. The combined redevelopment of social housing (pp. 83-115).

Marotta, N., \& Zirilli, O. (2015). Disastri e Catastrofi. Rischio, esposizione, vulnerabilità e resilienza. Milano: FrancoAngeli.

Montuori, M. (2016). E pluribus unum, in Angi B. (a cura di/edited by). Eutopia Urbana/Eutopia Urbanscape. Siracusa: Lettera Ventidue, pp. 11-43.

Montuori, M., Angi, B., Botti, M., \& Longo, O. (2012). "The rational maintenance of social housing (with a warlike modesty)". In Cities in transformation. Research \& stamp; design, Housing and the shape of the city (65-68), Politecnico di Milano, 7-10 giugno 2012, Milano.

Murie, A., Knorr-Siedow, T., \& Van Kempen, R. (2003). Large housing estates in Europe: General developments and theoretical backgrounds. RESTATE report. Urban and Regional Research Centre, Utrecht University. 
Paris, S., \& Bianchi, R. (2018). Ri-abitare il moderno. Il progetto per il rinnovo dell'housing. Macerata: Quodlibet.

Passoni, C. (2016). Holistic renovation of existing RC buildings: A framework for possible integrated structural interventions (Ph.D. thesis). University of Brescia.

Perriccioli, M. (2015). Re-cycling social housing, Ricerche per la rigenerazione sostenibile dell'edilizia residenziale sociale. Napoli: Clean.

Piano, R. (2014). Il rammendo delle periferie. IlSole24 Ore, domenica, 26 gennaio.

Scuderi, G. (2016). Adaptive building exoskeletons. A biomimetic model for the rehabilitation of social housing. International Journal of Architectural Research, 9(1), 134-143.

Zambelli, E. (2004). Ristrutturazione e trasformazione del costruito, Il Sole 24 Ore, Milano.

Open Access This chapter is licensed under the terms of the Creative Commons Attribution 4.0 International License (http://creativecommons.org/licenses/by/4.0/), which permits use, sharing, adaptation, distribution and reproduction in any medium or format, as long as you give appropriate credit to the original author(s) and the source, provide a link to the Creative Commons license and indicate if changes were made.

The images or other third party material in this chapter are included in the chapter's Creative Commons license, unless indicated otherwise in a credit line to the material. If material is not included in the chapter's Creative Commons license and your intended use is not permitted by statutory regulation or exceeds the permitted use, you will need to obtain permission directly from the copyright holder.

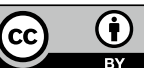

